\section{Strategies for Mycorrhizal Inoculation of Six Annual Bedding Plant Species}

\author{
Roger T. Koide ${ }^{1}$, Lena L. Landherr, Ylva L. Besmer, Jamie M. \\ Detweiler, and E. Jay Holcomb \\ Department of Horticulture, The Pennsylvania State University, University \\ Park, PA 16802-4200
}

Additional index words. Vesicular arbuscular mycorrhiza, Glomus intraradices, phosphate concentration, Tagetes patula, Impatiens walleriana, Salvia splendens, Petunia $\times$ hybrida, Coleus $\times$ hybridus, Viola $\times$ wittrockiana, formononetin

\begin{abstract}
We inoculated six common annual bedding plant species with the vesiculararbuscular mycorrhizal fungus Glomus intraradices Schenck \& Smith using two fertilizer $P$ concentrations ( 3 or $15 \mu \mathrm{g} \cdot \mathrm{mL}^{-1}$ ) and three inoculation timings (inoculation at sowing, at transplanting, or at both times). The plant species used were: Salvia splendens F. Sellow ex Roem. \& Schult. cv. Firecracker Rose; Impatiens walleriana Hook. f. cv. Sun and Shade Royal Red; Tagetes patula L. cv. Girls Golden; Petunia $\times$ hybrida Hort. Vilm.-Andr. cv. Freedom Blue; Coleus $\times$ hybridus Voss. cv. Jazz Salmon; and Viola $\times$ wittrockiana Gams. cv. Majestic Giant White. In general, Coleus, Petunia, and Viola were colonized more than were Impatiens, Tagetes, and Salvia. Inoculation at sowing required less inoculum than either of the other methods. Moreover, it was generally as effective in promoting colonization as double inoculation, and was often more effective than inoculation at transplanting. Mycorrhizal colonization was significantly reduced by the higher $P$ concentration. The use of Myconate ${ }^{\circledR}$, a water-soluble form of the flavonoid formononetin, significantly stimulated colonization in Salvia.
\end{abstract}

Annual bedding plants account for the largest sales volume in the majority of commercial greenhouses in Pennsylvania (Brumfield et al., 1993). The roots of most bedding plant species can be colonized by beneficial vesicular-arbuscular mycorrhizal (VAM) fungi (Tester et al., 1987), which increase the uptake of $\mathrm{P}$ into plants by providing additional absorbing surface area (Koide, 1991). Because most commercially available potting media lack mycorrhizal fungi, inoculation of greenhouse plants could theoretically be used to maintain a high rate of $\mathrm{P}$ uptake while reducing the use of $\mathrm{P}$ fertilizer.

The benefit from mycorrhizal colonization may be related to the amount of colonization established early in the seedling stage of plant growth (Boswell et al., 1998; Pedersen et al., 1991). However, some attempts to colonize roots growing in soilless media have resulted in low levels of colonization (Biermann and Linderman, 1983a; Johnson and Hummel, 1986; Nemec, 1987; Pedersen et al., 1991). There are, therefore, few documented examples of the successful use of VAM fungi in horticultural production, particularly in floriculture (Chang, 1994; Miller et al., 1986).

Many factors determine the rate and extent

Received for publication 6 July 1998. Accepted for publication 7 Apr. 1999. We thank the American Floral Endowment for providing funding for this project and Dr. John Kelly of Natural Product Technologies, Inc., for providing the Myconate $\AA$. The cost of publishing this paper was defrayed in part by the payment of page charges. Under postal regulations, this paper therefore must be hereby marked advertisement solely to indicate this fact.

${ }^{1}$ To whom reprint requests should be addressed. Fax: (814) 863-6139; e-mail: rxk13@psu.edu of mycorrhizal colonization. Certainly, variability in the amount of colonization occurs among plant species (Koide and $\mathrm{Li}, 1991$; Plenchette et al., 1983; Wang et al., 1993). The developmental stage at which inoculation occurs may also affect colonization. For example, Hepper (1988) found that Trifolium dubium Sibth. seedlings could not be colonized $5 \mathrm{~d}$ after germination. High concentrations of fertilizer $\mathrm{P}$ may also reduce mycorrhizal colonization (Biermann and Linderman, 1983a; Koide and Li, 1990). Finally, flavonoid compounds such as formononetin stimulate colonization (Siqueira et al., 1991) and their use may be practical in the greenhouse.

There were four objectives in this study. The first was to determine the degree of variability among annual bedding plant species in their ability to become colonized by mycorrhizal fungi when growing in a soilless potting medium. The second was to determine if inoculating at different seedling growth stages influenced the degree of colonization. This is relevant to the production of bedding plants because their seeds are typically sown in plug flats and the resulting seedlings are transplanted into larger containers for the retail market. The third objective was to determine how fertilizer $\mathrm{P}$ concentrations affect colonization, and the fourth was to determine if a commercially available water-soluble form of formononetin (trade name: Myconate ${ }^{\circledR}$ ) could stimulate mycorrhizal colonization.

\section{Materials and Methods}

Two experiments were conducted. In the first we determined the effects of plant species, fertilizer $\mathrm{P}$ concentration $\left(3\right.$ or $15 \mu \mathrm{g} \cdot \mathrm{mL}^{-1}$ ), and inoculation timing (inoculation at sowing, at transplanting, or at both times) on mycorrhizal colonization. In the second, we determined the effects of Myconate on mycorrhizal colonization of the species that exhibited the lowest colonization in Expt. 1.

General methods. Seeds were purchased from Grimes Seeds (Concord, Ohio) and sown into "plug" flats containing two hundred 10$\mathrm{mL}$ "plug" compartments. The flats were placed on moistened capillary matting in the greenhouse and the seedlings were irrigated with distilled water as needed and grown without supplementary light. Air temperatures were maintained between 24 and $29^{\circ} \mathrm{C}$ to promote germination, then reduced to between 21 and $25{ }^{\circ} \mathrm{C}$ for the remainder of the experiment. Mycorrhizal colonization of root samples was assessed using the line-intersection method following clearing and staining as described in Koide and Mooney (1987). Data were analyzed using the analysis of variance (ANOVA) procedures of the Statgraphics programs (STSC, Inc., 1991). Means were separated using the least significant difference method. Differences were considered significant when $P \leq 0.05$.

Expt. 1. Effects of plant species, fertilizer $P$ concentration, and inoculation timing on mycorrhizal colonization. Seeds of all six species (see Abstract) were sown between 24 Mar. and 4 Apr. 1997 into plug flats containing either mycorrhizal (M) or control (0) media.

The $\mathrm{M}$ medium consisted of a mixture of 1 Pro-Mix PGX® (Premier, Riviere-du-Loup, Que., Canada) : 1 Mycorise HX ${ }^{\circledR}$ (Premier) (by volume). Mycorise HX consists of $\approx 90 \%$ perlite and $10 \%$ peat and contains colonized root pieces (plant species is proprietary) and about two spores per $\mathrm{cm}^{3}$ of Glomus intraradices Schenck \& Smith. It contains essentially no available nutrients. Pro-Mix PGX consists of $\approx 60 \%$ to $70 \%$ peat, the balance being vermiculite, and contains a blend of macronutrients and micronutrients for early seedling growth. The control (0) medium consisted of a mixture of 1 Pro-Mix PGX : 1 Growing Mix \#1® (Ball Seed, West Chicago, Ill.), which, like Mycorise HX, contains no nutrients and provides a similar degree of aeration. Growing Mix \#1 consists of a mixture of bark, perlite, and vermiculite.

When the second true leaf appeared, root samples were taken from randomly selected Mand 0 seedlings to determine variation among species in mycorrhizal colonization. $\mathrm{M}$ and 0 plug seedlings were also transplanted into larger containers $(6 \times 5 \times 5.5 \mathrm{~cm}$ deep $)$, commonly called six-packs. The time from sowing to transplanting varied with species $(19,26$, 27, 35, 35, and $35 \mathrm{~d}$ for Tagetes, Salvia, Petunia, Impatiens, Coleus, and Viola, respectively). The media used in the larger containers either contained mycorrhiza inoculum (M) or did not $(0)$, resulting in four inoculation combinations (plug/container: 0/0, 0/M, M/0, $\mathrm{M} / \mathrm{M})$. The $\mathrm{M}$ medium for the larger containers consisted of 50\% Mycorise HX, the balance peat, and Growing Mix \#1,. The control (0) medium consisted of perlite, peat, and Growing Mix \#1. Both $\mathrm{M}$ and 0 media for the 
containers contained no additional nutrients and differed from the plug media by providing more aeration.

The containers were distributed on a total of four flood and drain benches. We used a soluble nutrient solution (Peters Excel, 15-220 : 15.0N-0.9P-16.6K, Scotts-Sierra Horticultural Products, Marysville, Ohio) that contained micronutrients and was mixed to yield a $\mathrm{N}$ concentration of $50 \mu \mathrm{g} \cdot \mathrm{mL}^{-1} \mathrm{~N}$ ( $\mathrm{N}$ was $10 \%$ ammonia, $85 \%$ nitrate, $5 \%$ urea). Two benches were given no additional $\mathrm{P}$ and thus had a $\mathrm{P}$ concentration of $3.0 \mu \mathrm{g} \cdot \mathrm{mL}^{-1}$ as phosphate. Two other benches were given $\mathrm{NaH}_{2} \mathrm{PO}_{4} \cdot \mathrm{H}_{2} \mathrm{O}$, resulting in a $\mathrm{P}$ concentration of $15.0 \mu \mathrm{g} \cdot \mathrm{mL}^{-1}$. All nutrient solutions were adjusted to $\mathrm{pH} 5.8-6.0$ with $\mathrm{HCl}$ or $\mathrm{NaOH}$ before each watering. After the plants became established, the $\mathrm{N}$ concentration for all benches was increased to $100 \mu \mathrm{g} \cdot \mathrm{mL}^{-1}$ by addition of $\mathrm{Ca}\left(\mathrm{NO}_{3}\right)_{2}$.

There were six replicate containers (sixpacks) of Salvia, Impatiens, Tagetes, Petunia, and Viola per treatment combination, a single container (six-pack) serving as the experimental unit. For those five species, there were a total of 240 containers: five species $\times$ two plug inoculation treatments, $\times$ two container inoculation treatments $\times$ two container $P$ concentrations $\times$ six containers. There were six containers for each of the low $\mathrm{P}$ treatment combinations for Coleus, but only three containers for each of the high $\mathrm{P}$ treatment combinations.

The six plants in each container were harvested when they attained retail size (between 21 and 27 May 1997 for Salvia, Impatiens, Tagetes, and Petunia and between 11 and 12 June 1997 for Viola and Coleus). Shoot dry weight and mycorrhizal colonization were determined on two randomly selected plants per container. The average value of the two was taken to represent the replicate. Colonization data were analyzed using species, inoculation timing $(0 / \mathrm{M}, \mathrm{M} / 0, \mathrm{M} / \mathrm{M})$, and $\mathrm{P}$ concentration as factors. All $0 / 0$ plants were nonmycorrhizal. Shoot dry weights were analyzed separately for each species using plug inoculation treatment, container inoculation treatment, and fertilizer $\mathrm{P}$ concentration as factors.

Expt. 2. Effect of Myconate on mycorrhizal colonization. Seeds of Salvia splendens cv. Firecracker Rose were sown on 2 June 1997 into two plug flats (described above) containing a 1 PGX : $1 \mathrm{HX}$ mixture (by volume) as described for the plug seedlings in Expt. 1. On 10 June 1997 (emergence) the flats were removed from the mat. We applied $500 \mathrm{~mL}$

Table 1. Mean colonization of roots of plug seedlings by mycorrhizal fungi at time of transplanting into six-pack containers.

\begin{tabular}{lcc}
\hline Genus & Colonization $(\%)$ & $\mathrm{n}$ \\
\hline Tagetes & $24.0 \mathrm{a}^{\mathrm{z}}$ & 3 \\
Salvia & $45.7 \mathrm{~b}$ & 3 \\
Impatiens & $48.3 \mathrm{~b}$ & 3 \\
Petunia & $54.5 \mathrm{bc}$ & 2 \\
Viola & $73.3 \mathrm{~cd}$ & 3 \\
Coleus & $86.3 \mathrm{~d}$ & 3 \\
\hline
\end{tabular}

${ }^{\mathrm{z}}$ Mean separations by Fisher's protected LSD $(P \leq$ $0.05)$. distilled water to the single control flat and 500 $\mathrm{mL}$ of a $100 \mu \mathrm{g} \cdot \mathrm{mL}^{-1}$ solution of Myconate, a water-soluble form of formononetin (Natural Product Technologies, Okemos, Mich.), to the other flat. The concentration of Myconate was chosen based on other experiments in which we demonstrated that $100 \mu \mathrm{g} \cdot \mathrm{mL}^{-1}$ was as effective as $1000 \mu \mathrm{g} \cdot \mathrm{mL}^{-1}$, and significantly more effective than $10 \mu \mathrm{g} \cdot \mathrm{mL}^{-1}$, in promoting mycorrhizal colonization. Flats were placed back onto capillary matting until 17 June when the treatments were reapplied. On 27 June (25 $\mathrm{d}$ after sowing), seven pairs of plants were randomly selected from each of the flats to assess mycorrhizal colonization. On 4 July ( 32 d after sowing) 10 pairs of plants were randomly selected for assessment of mycorrhizal colonization. Root samples were assessed for mycorrhizal colonization as above. Colonization data from each harvest were analyzed separately by single-factor (treatment) ANOVA.

\section{Results and Discussion}

Expt. 1. Effects of plant species, fertilizer $P$ concentration, and inoculation timing on mycorrhizal colonization. The roots of noninoculated $(0)$ plants were not colonized by mycorrhizal fungi at transplanting or at final harvest. Significant variation among plant species existed in the amount of mycorrhizal colonization of inoculated plug seedlings (Table 1). Coleus and Viola were the most highly colonized while Tagetes was the least. Salvia, Impatiens, and Petunia were intermediate. These colonization levels correspond well to the duration between sowing and transplanting; slower-growing seedlings were exposed to the inoculum for longer periods of time and thus had a greater opportunity to become infected. Seedling development rate, therefore, appears to be an important factor helping to determine the utility of mycorrhizal inoculation.

There was a significant three-way interaction among species, inoculation timing, and phosphorus concentration for mycorrhizal colonization at final harvest (Table 2, Fig. 1). Significant variation existed among species, but the ranking of species changed depending on $\mathrm{P}$ concentration and inoculation timing. In general, however, Coleus, Petunia, and Viola were among the most colonized, while Impatiens, Tagetes, and Salvia were among the least colonized. Thus, the colonization ranking established among seedlings appeared to persist into the later stage of development.

The amount of colonization can be correlated with the benefit derived from colonization in P-deficient soils for citrus rootstocks (Graham et al., 1991) and for wheat (Triticum aestivum L.) cultivars (Azcon and Ocampo, 1981). However, this may not be true for the wide selection of bedding plant species in this study. Several physiological and morphological traits of root systems may determine the degree to which a plant benefits from mycorrhizal colonization (Koide, 1991), and these may differ markedly among plant species.

The higher $\mathrm{P}$ concentration significantly reduced mycorrhizal colonization (Table 2 , Fig. 1). The only exceptions to this occurred for Salvia and Viola using the M/0 inoculation timing. Our data suggest that moderate concentrations of $\mathrm{P}$ applied to peat-based media may have strong negative effects on mycorrhizal colonization of the roots of the six species investigated. In general, high $P$ concentrations limit mycorrhizal colonization (Koide and $\mathrm{Li}, 1990$ ), at least partly by limiting extraradical hyphal development and the number of hyphal penetrations into the root (Schwab et al., 1983). In some cases, concentrations of $\mathrm{P}$ significantly $>15 \mu \mathrm{g} \cdot \mathrm{mL}^{-1}$ can be added to mineral soil with less negative consequences for mycorrhizal colonization (MacLeod et al., 1986; Schwab et al., 1983), perhaps because mineral soils buffer $\mathrm{P}$ concentrations by $\mathrm{P}$ fixation (Nye and Tinker, 1977). In sand, which has a small capacity to buffer $P$, even small concentrations of $\mathrm{P}$ (as low as $1 \mu \mathrm{g} \cdot \mathrm{mL}^{-}$ ${ }^{1} \mathrm{P}$ ) can reduce mycorrhizal colonization (Koide and $\mathrm{Li}, 1990)$. In peat-based media, which have little $\mathrm{P}$ buffering capacity (Havis and Baker, 1985; Lemaire and Dartigues, 1988), establishment of the mycorrhizal symbiosis and the development of external mycorrhizal hyphae may be particularly sensitive to nutrient solution $\mathrm{P}$ concentrations (M. Kling, personal communication). Thus, a significant reduction in mycorrhizal colonization may result from the attempt to maximize plant growth by applying high concentrations of $\mathrm{P}$ fertilizer

Table 2. Analysis of variance for colonization of roots by mycorrhizal fungi at the time of harvest from sixpack containers (see Fig. 1). Only data for the $0 / \mathrm{M}, \mathrm{M} / 0$, and $\mathrm{M} / \mathrm{M}$ treatment combinations were analyzed; data for the $0 / 0$ treatment, which is entirely nonmycorrhizal, were not analyzed. Data were lntransformed prior to analysis.

\begin{tabular}{lrcrrr}
\hline Source of variation & df & Sum of squares & Mean square & F-ratio & Significance level \\
\hline Main effects & 5 & 12.41 & 2.48 & 29.71 & 0.0001 \\
$\quad$ A: Species & 2 & 4.06 & 2.03 & 24.26 & 0.0001 \\
B: Inocul. procedure & 1 & 36.95 & 36.94 & 441.96 & 0.0001 \\
C: P concentration & & & & & \\
Interactions & 10 & 1.63 & 0.16 & 1.96 & 0.0449 \\
AB & 5 & 2.35 & 0.47 & 5.61 & 0.0001 \\
AC & 2 & 0.35 & 0.18 & 2.11 & 0.1260 \\
BC & 10 & 2.47 & 0.25 & 2.96 & 0.0025 \\
ABC & 112 & 9.36 & 0.08 & & \\
Residual & 147 & 73.81 & & & \\
Total & 11 & & & &
\end{tabular}

${ }^{2}$ Refers to 0/M, M/0, and M/M inoculations (see Materials and Methods). 
to peat-based media. The utility of mycorrhizal fungi for $\mathrm{P}$ uptake under these circumstances may be low.

Inoculation timing did not significantly affect mycorrhizal colonization for either Tagetes or Petunia, at either 3 or $15 \mu \mathrm{g} \cdot \mathrm{mL}^{-1} \mathrm{P}$. The same was true for Coleus at $3 \mu \mathrm{g} \cdot \mathrm{mL}^{-1}$. However, for the other seven cases, inoculation timing had a significant effect. Generally, inoculation both at sowing and at transplanting $(\mathrm{M} / \mathrm{M})$ resulted in the highest colonization, inoculation only at transplanting $(0 / \mathrm{M})$ resulted in the least colonization, and inoculation only at sowing $(\mathrm{M} / 0)$ was nearly as effective as inoculating at both times. Inoculation at sowing $(\mathrm{M} / 0)$ was superior to inoculation at transplanting $(0 / \mathrm{M})$ and just as effective as inoculation at both stages $(\mathrm{M} / \mathrm{M})$ for Impatiens at $3 \mu \mathrm{g} \cdot \mathrm{mL}^{-1} \mathrm{P}$, and for Salvia and Viola at $15 \mu \mathrm{g} \cdot \mathrm{mL}^{-1} \mathrm{P}$. The effect of inoculation at sowing $(\mathrm{M} / 0)$ was intermediate between that of colonization only at transplanting $(0 / \mathrm{M})$ and at both stages (M/M) for Viola at $3 \mu \mathrm{g} \cdot \mathrm{mL}^{-1} \mathrm{P}$, and for Impatiens and Coleus at $15 \mu \mathrm{g} \cdot \mathrm{mL}^{-1} \mathrm{P}$.

Because the $\mathrm{M} / 0$ inoculation timing used, by far, the smallest volume of inoculum per plant, the most practical inoculation procedure appears to be addition of inoculum to the plug trays. However, a decrease in shoot dry weight was associated with this inoculation timing on some occasions, although the decrease was less than for plants inoculated at transplanting (Table 3, Fig. 2). The $15 \mu \mathrm{g} \cdot \mathrm{mL}^{-1} \mathrm{P}$ concentration resulted in a significant increase, and inoculation at transplanting a significant decrease, in shoot weight for all species. Inoculation at sowing ameliorated the negative effect of inoculation at transplanting for Salvia, but reduced shoot weight in Coleus and Viola. There was a significant three-way interaction for Impatiens. At $3 \mu \mathrm{g} \cdot \mathrm{mL}^{-1} \mathrm{P}$ concentration, both inoculation at sowing and at transplanting reduced shoot weight, but the effect was strongest for inoculation at transplanting. At $15 \mu \mathrm{g} \cdot \mathrm{mL}^{-1} \mathrm{P}$ concentration, however, shoot dry weight was reduced only when plants were inoculated at both times.

The negative or insignificant effects on shoot growth following inoculation of plants in soilless media that we obtained in this study have also been observed in other studies (Biermann and Linderman, 1983a, 1983b). In some cases, growth depressions have been attributed to the loss of photosynthate from the host to the fungus (Buwalda and Goh, 1982). This does not appear to be the case in our study because growth depressions occurred even with the high $\mathrm{P}$ concentration that supported very low amounts of colonization. Growth depressions have also been associated with other soil-dwelling microorganisms accompanying mycorrhizal fungal propagules (Koide and $\mathrm{Li}, 1990)$. Even given low concentrations of $\mathrm{P}$, mycorrhizal fungi may be incapable of increasing plant $\mathrm{P}$ uptake when $\mathrm{P}$ is supplied in a readily soluble form to a medium that does not fix $P$. The utilization of a medium with greater P-buffering capacity, in combination with mycorrhizal fungi, may provide adequate $\mathrm{P}$ nutrition while reducing the leaching of $\mathrm{P}$ from containers.

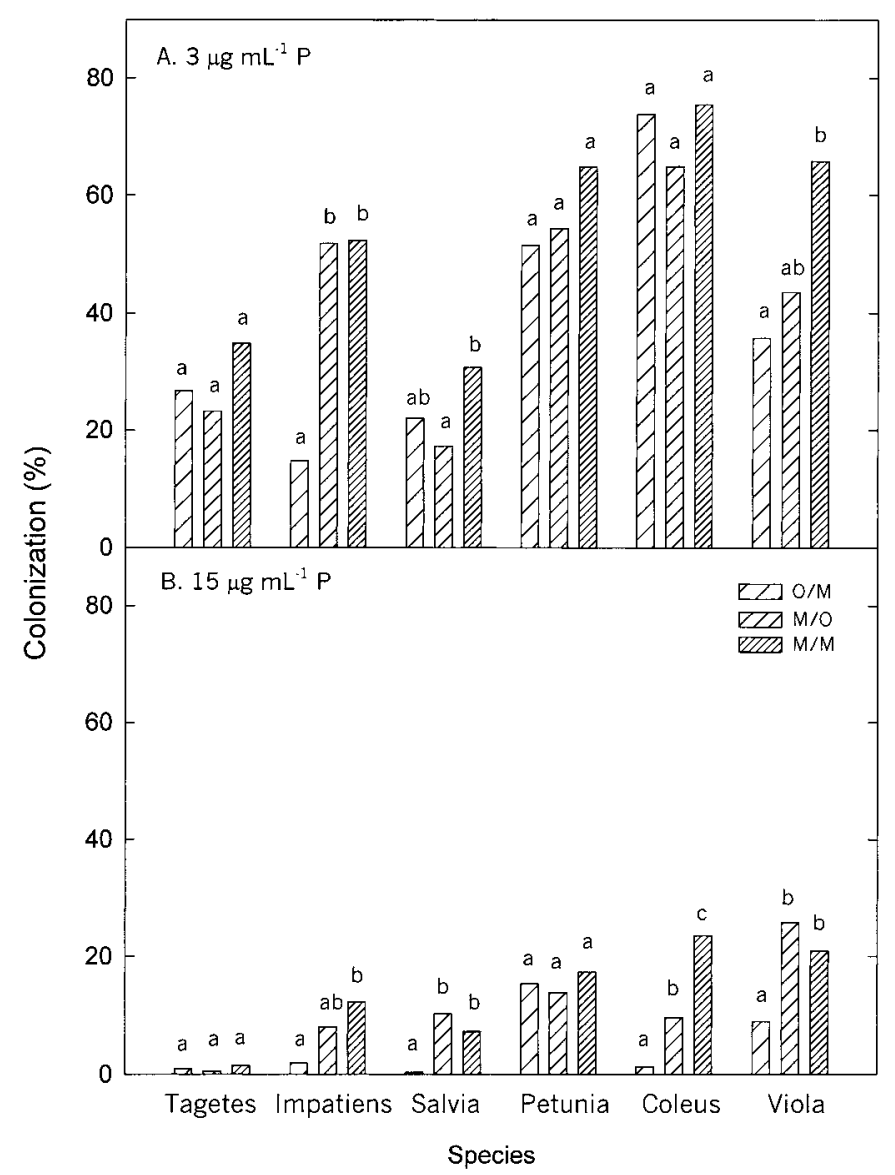

Fig. 1 Effects of level of $\mathrm{P}$ applied and timing of inoculation with mycorrhizal fungi $(0 / \mathrm{M}=$ inoculation at transplanting, $\mathrm{M} / 0=$ inoculation at sowing, $\mathrm{M} / \mathrm{M}=$ inoculation at both times) on mean root colonization (\% of root length) in six plant species. Mean separations (abc) within species and $\mathrm{P}$ levels were accomplished by $\mathrm{LSD}_{0.05}$ following ANOVA. $\mathrm{n}=6$ for all treatment combinations except low P Coleus treatment combinations for which $\mathrm{n}=3$. Expt. 1 .

Table 3. Analysis of variance for shoot dry weight of seedlings of six species at the time of harvest from sixpack containers. Numbers indicate levels of significance of $F$ values.

\begin{tabular}{lcccccr}
\hline & \multicolumn{5}{c}{ Species } \\
\cline { 2 - 7 } Source of variation & Tagetes & Impatiens & Petunia & Salvia & Coleus & Viola \\
\hline Main effects & NS & 0.0001 & NS & 0.0002 & 0.0039 & 0.0386 \\
$\quad$ A: Sowing inoculation & 0.0001 & 0.0001 & 0.0001 & 0.0007 & 0.0192 & 0.0001 \\
B: Transplant inoculation & 0.0001 & 0.0001 & 0.0001 & 0.0001 & 0.0005 & 0.0001 \\
C: P concentration & & & & & & \\
Interactions & NS & NS & NS & 0.0066 & NS & NS \\
AB & NS & 0.0316 & NS & NS & NS & NS \\
AC & NS & NS & NS & NS & NS & NS \\
BC & NS & 0.0001 & NS & NS & NS & NS \\
ABC & & & & & \\
\hline
\end{tabular}

${ }^{\mathrm{Ns}}$ Nonsignificant at $P \leq 0.05$.

Expt. 2. Effect of Myconate on mycorrhizal colonization. Salvia was the most difficult species to colonize in Expt.1. In Expt. 2, mycorrhizal colonization of control plants (those given only water) was not significantly different from those treated with Myconate, $25 \mathrm{~d}$ after sowing, but by $32 \mathrm{~d}$, treated plants had significantly higher mycorrhizal colonization (Fig. 3). Siqueira et al. (1991) reported similar results using formononetin. This suggests that smaller concentrations of inoculum, at lower cost, could be used to produce significant mycorrhizal colonization if Myconate were applied. Currently, however, we know little about the independent effects of formononetin or Myconate on plants or on parasitic and pathogenic fungi. More descriptive and mechanistic research on formononetin is needed.

\section{Conclusions}

The utility of inoculating with mycorrhizal fungi in peat-based media fertilized with soluble P may be limited, particularly if the goal is to reduce the use of P fertilizer in the greenhouse. Further studies on alternative substrates with greater P-buffering capacity may prove useful. Despite the lack of growth increase as a consequence of mycorrhizal colo- 

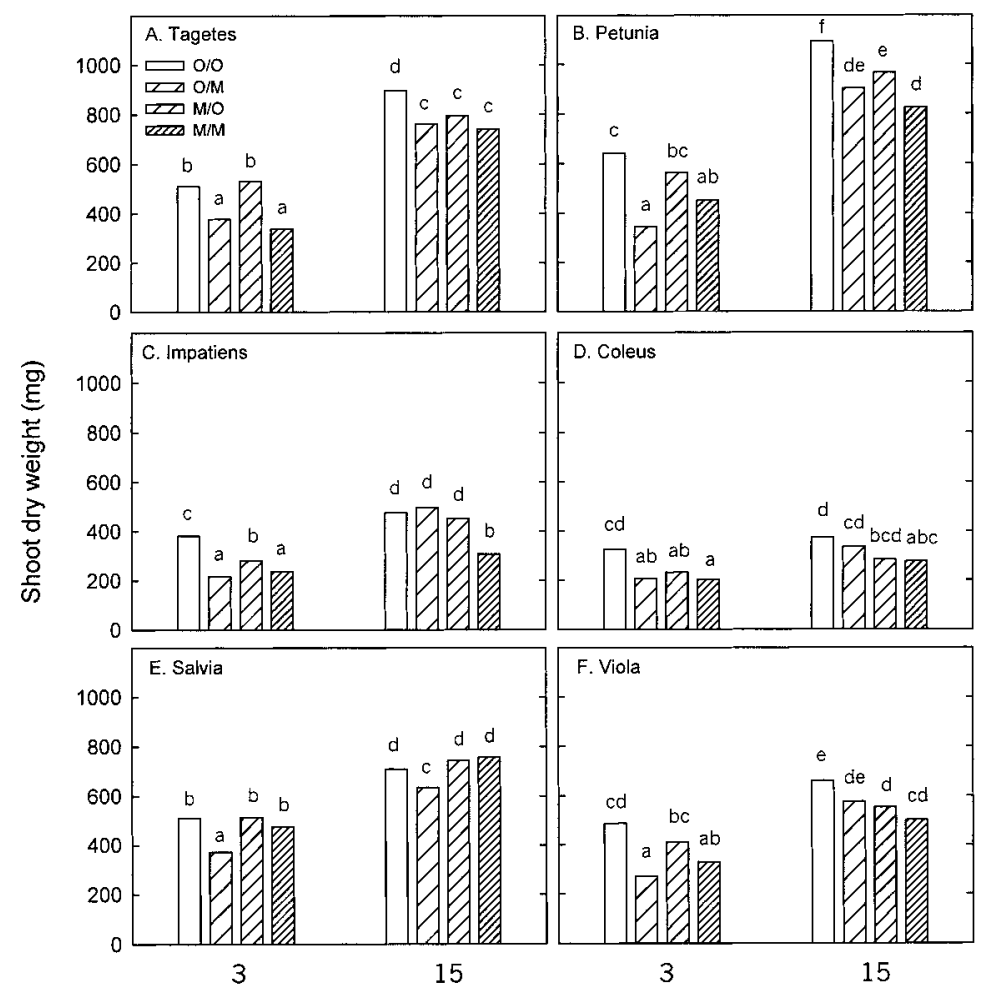

15

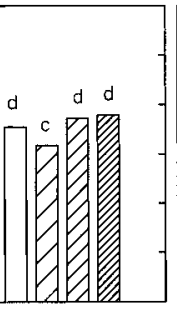

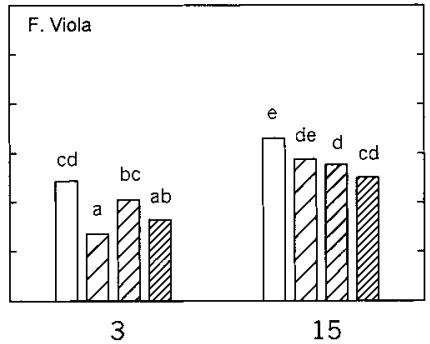

15
$\mathrm{P}$ applied $\left(\mu \mathrm{g} \mathrm{mL}^{-1}\right)$

Fig. 2 Effects of level of P applied and timing of inoculation with mycorrhizal fungi (see Fig. 1) on mean shoot dry weight of six plant species. Mean separations ( $a b c)$ within species and $\mathrm{P}$ levels were accomplished by $\mathrm{LSD}_{0.05}$ following ANOVA. $\mathrm{n}=6$ for all treatment combinations except low P Coleus treatment combinations for which $n=3$. Expt. 1.

nization in this study, inoculation may still be beneficial, depending on the medium into which the plants are transplanted. Because many bedding plants will be transplanted into mineral soil in which $\mathrm{P}$ buffering may be strong, inoculation at the greenhouse stage may eventually prove to be beneficial during the outplanting stage.

\section{Literature Cited}

Azcon, R. and J.A. Ocampo. 1981. Factors affecting the vesicular-arbuscular infection and mycorrhizal dependency of thirteen wheat cultivars. New Phytol. 87:677-685.

Biermann, B. and R.G. Linderman. 1983a. Effect of container plant growth medium and fertilizer phosphorus on establishment and host growth response to vesicular-arbuscular mycorrhizae. J. Amer. Soc. Hort. Sci. 108:962-971.

Biermann, B. and R.G. Linderman. 1983b. Increased geranium growth using pretransplant inoculation with a mycorrhizal fungus. J. Amer. Soc. Hort. Sci. 108:972-976.

Boswell, E.P., R.T. Koide, D.L. Shumway, and H.D. Addy. 1998. Winter wheat cover cropping, VA mycorrhizal fungi and maize growth and yield. Agr. Ecosyst. Environ. 67:55-65.

Brumfield, R.G., L.E. Sim, P. Ford, C. Frumento, and D.J. Wolnick. 1993. Pennsylvania greenhouse survey. The Pennsylvania State Univ., College of Agr. Sci. Coop. Ext., Circ. 405.

Buwalda, J.G. and K.M. Goh. 1982. Host-fungus competition for carbon as a cause of growth depressions in vesicular-arbuscular mycorrhizal ryegrass. Soil Biol. Biochem. 14:103-106.

Chang, D.C.N. 1994. What is the potential for management of vesicular-arbuscular mycorrhizae in horticulture?, p. 187-190. In: A.D. Robson, L.K. Abbott, and N. Malajczuk (eds.). Management of mycorrhizas in agriculture, horticulture and forestry. Kluwer Acad., Dordrecht, The Netherlands.

Graham, J.H., D.M. Eissenstat, and D.L. Drouillard. 1991. On the relationship between a planta's mycorrhizal dependency and rate of vesiculararbuscular mycorrhizal colonization. Funct. Ecol. 5:773-779.

Havis, J.R. and J.H. Baker. 1985. Influence of liming rate on phosphorus leaching from a peatsand medium. J. Environ. Hort. 3:74-76.

Hepper, C. 1988. Factors controlling the vesiculararbuscular mycorrhizal (VAM) infection of roots. Karstenia 28:40.

Johnson, C.R. and R.L. Hummel. 1986. Influence of media on endomycorrhizal infection and growth response of Severinia buxifolia. Plant Soil 93:3542.

Koide, R.T. 1991. Nutrient supply, nutrient demand and plant response to mycorrhizal infection. New Phytol. 117:365-386.

Koide, R.T. and M. Li. 1990. On host regulation of the vesicular-arbuscular mycorrhizal symbiosis. New Phytol. 114:59-64.

Koide, R.T. and M. Li. 1991. Mycorrhizal fungi and the nutrient ecology of three oldfield annual plant species. Oecologia 85:403-412.

Koide, R.T. and H.A. Mooney. 1987. Spatial variation in inoculum potential of vesicular-arbuscular mycorrhizal fungi caused by formation of gopher mounds. New Phytol. 107:173-182.

Lemaire, F. and A. Dartigues. 1988. Phosphorus assimilability in french brown peat. Acta Hort. 221:383-394.

MacLeod, W.J., A.D. Robson, and L.K. Abbott. 1986. Effects of phosphate supply and inoculation with a vesicular-arbuscular mycorrhizal fungus on the death of the root cortex of wheat, rape and subterranean clover. New Phytol. 103:349-357.

Miller, J.C., Jr., S. Rajapakse, and R.K. Garber. 1986. Vesicular-arbuscular mycorrhizae in vegetable crops. HortScience 21:974-984.

Nemec, S. 1987. VA mycorrhizae in horticultural systems, p. 193-211. In: G.R. Safir (ed.). Ecophysiology of VA mycorrhizal plants. CRC Press, Boca Raton, Fla.

Nye, P.H., and P.B. Tinker. 1977. Solute movement in the soil-root system. Univ. California Press, Berkeley.

Pedersen, C.T., G.R. Safir, S. Parent, and M. Caron. 1991. Growth of asparagus in a commercial peat mix containing vesicular-arbuscular mycorrhizal (VAM) fungi and the effects of applied phosphorus. Plant Soil 135:75-82.

Plenchette, C., J.A. Fortin, and V. Furlan. 1983. Growth responses of several plant species to mycorrhizae in a soil of moderate P-fertility. II. Soil fumigation induced stunting of plants corrected by reintroduction of the wild endomycorrhizal flora. Plant Soil 70:211-217.

Schwab, S.M., J.A. Menge, and R.T.Leonard. 1983. Comparison of stages of vesicular-arbuscular mycorrhiza formation in sudangrass grown at two levels of phosphorus nutrition. Amer. J. Bot. 70:1225-1232.

Siqueira, J.O., G.R. Safir, and M.G. Nair. 1991. Stimulation of vesicular-arbuscular mycorrhiza formation and growth of white clover by flavonoid compounds. New Phytol. 118:87-93.

STSC, Inc. 1991. Statgraphics statistical graphics system, Version 51. STSC, Inc., Rockville, Md.

Tester, M., S.E. Smith, and F.A. Smith. 1987. The phenomenon of "nonmycorrhizal" plants. Can. J. Bot. 65:419-431.

Wang, H., S. Parent, A. Gosselin, and Y. Desjardins. 1993. Vesicular-arbuscular mycorrhizal peatbased substrates enhance symbiosis establishment and growth of three micropropagated species. J. Amer. Soc. Hort. Sci. 118:896-901. 